\title{
The Yeti - not a Snowman
}

\author{
J. A. McNeely, E. W. Cronin and H. B. Emery
}

In this survey of the evidence for the yeti's existence and likely identity, the authors point out that the misleadingly named 'abominable snowman' is not a creature of the snows at all, but should be looked for in the dense Himalayan forests, which could support it. At present the authors are engaged in studying one such forest area, the Arun Valley between Everest and Kanchenjunga, on behalf of the Thailand Association for the Conservation of Wildlife. In January this year they reported having had 'three incidents involving yeti so far, but only one yielded solid evidence'. On December 18 Cronin's and Emery's tent on a ridge in the upper Arun 'was visited by an animal which left tracks that are not referable to any known animal'- see the photograph by Jeffrey McNeely on the next page.

Crossing the Menlung Glacier near the Tibet-Nepal border, Eric Shipton and Michael Ward, of the 1951 British Mount Everest Reconnaissance Expedition, came across a long line of strange footprints. 'Yeti, sir, yeti', said their Sherpa porters. 'At the point where we came across the tracks', says Shipton, 'there was evidence of two creatures moving together. The tracks were side by side for part of the way and then crisscrossed. They were extremely fresh-probably they had been made only a few hours before we had found them and certainly on the same day. I particularly noted where one of the creatures had jumped a crevasse, a distance of about three feet. There was a mark of its takeoff and on the other side a clear imprint of where it had dug its toes in on landing.'

Shipton's photograph has become the type specimen of yeti footprints, and can be considered an indirect definition of the animal that made it. As Dr Toni Hagen, who spent eight years conducting a geological survey of Nepal for the United Nations, says, 'We know today only that the yeti must exist; for the tracks on the glaciers and in the snow are undoubtedly made by a living creature'. The footprints are not referable to any known animal; the unknown animal that made the print is, by definition, the yeti.

Over fifty mountaineers and naturalists have reported yeti footprints, including such famous names in Himalayan mountaineering as Sir John Hunt, H.W. Tilman, Sir C.K. HowardBury, Dr Norman Dyhrenfurth, and Sir Edmund Hillary. 'The authenticity of these reports cannot be disputed', says the British primatologist, Dr Vernon Reynolds, 'and indeed are corroborated by photographs showing what could be anthropoid footmarks, with bipedal progression'.

The reports of yeti footprints tend to be consistent, describing the tracks as occurring in a quite natural manner, following the least strenuous route, seemingly heading for a known destination. 

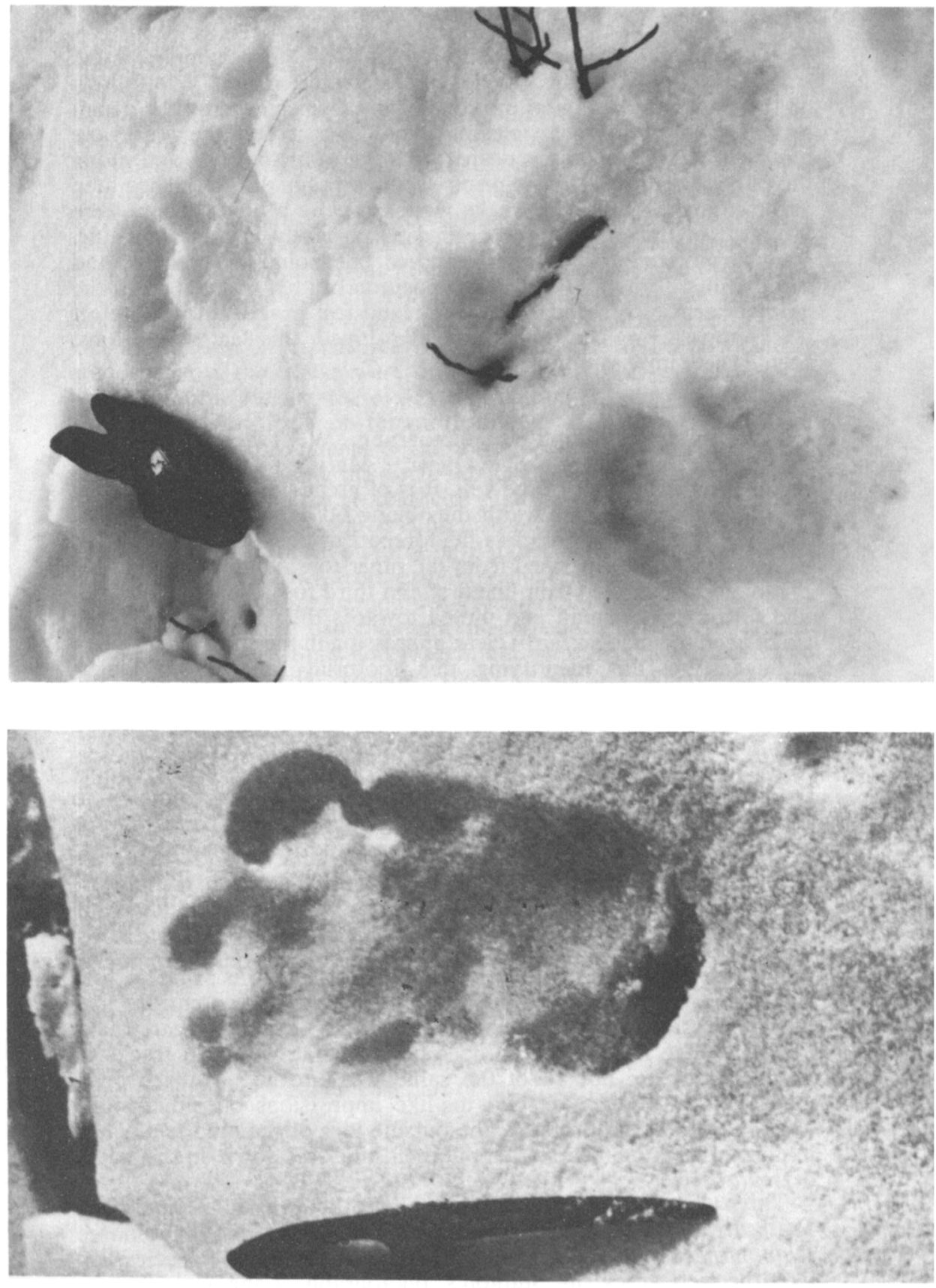
The London Daily Mail Expedition of 1954, for example, found tracks near the Khumbu Glacier in the Everest region. 'We followed the tracks to the lateral moraine of the glacier, where they disappeared. Two prints were clearer than the rest and the toes were quite visible. There was a deeper depression at the heel and along the outside of the foot. The prints were certainly 10-11 inches long and 5-6 inches wide; the tracks were made by a biped. There were 80 yards of tracks which proceeded purposefully in a straight line, showing no trace of "stagger", and at one point the creature had stood still with its two feet in the position of "ten to two". Had the animal been four-footed, placing its hind feet exactly in its forefeet tracks thus giving the impression of a biped, this feat would have been a sheer impossibility'.

\section{A Reconstruction}

On the basis of Shipton's photograph, W. Tschernsky of the Zoology Department of Queen Mary College, London, reconstructed the foot of the yeti. It is of great size, $12 \frac{1}{2}$ inches long and $7 \frac{1}{2}$ inches wide, the width thus being 60 per cent of the length. The heel is nearly as broad as the forepart of the sole. The great toe is very thick and separated from the other toes, with the second toe the longest, separated from the first and third toes. The third, fourth, and fifth toes are small and united towards their bases, though the tip of each toe made a fairly clear impression in the snow.

Suggestions for identifying this footprint range from langur monkeys to bears, large eagles, and foxes jumping on all fours; but the controversy continues, with responsible authorities stating it is a langur monkey and others that it is surely a bear.

Examination of the evidence suggests that there is little support for either bears or langurs. Several forms of bear are known to inhabit the Himalayas, including the 'blue bear' Ursus arctos pruinosus, the 'red bear' $U$. a. isabellinus, and the Himalayan black bear Selenarctos thibetanus. Tracks of these bears have been occasionally confused with yeti tracks. In 1937 F.S. Smythe found what were alleged to be yeti tracks: 'There were the well defined imprints of 5 toes $1 \frac{1}{2}$ ins long and $\frac{3}{4}$ in. broad, which, unlike human toes, were arranged symmetrically. Lastly, there was what at first sight appeared to be the impression of a heel, with two curious toelike impressions on either side', a description that fits bear tracks very well (see Figure 2), but does not coincide with yeti tracks at all. Yeti toes are not all of the same size, are not arranged symmetrically, and lack the 'two toe-like impressions on either side'. The 'extra toes' are probably the outside toes of the hind feet, since in normal walking, bears often put their hind feet down on the prints of their forefeet.

Three forms of langur have been suggested-Himalayan Presbytis entellus achilles; Kangar $P$. e. ajax; and snub-nosed Rhinopithecus roxellanae. But no langur tracks, of any species, are like the yeti track in Shipton's photograph. Langur prints are shorter, seldom longer than 8 ins (as compared to $12 \frac{1}{2}$ ins for yeti), relatively narrower, with a width/length ratio of about 25 per cent 
(compared to about 60 per cent for yeti), have much longer toes, averaging about 25 per cent of the foot length (compared to about 15 per cent for yeti), and have very different musculature of the foot. The footprint photographed by Shipton seems to resemble most closely that of the mountain gorilla, which lives at similar altitudes in the rich montane forests of central Africa: see figure 2.

A frequent comment about the prints is that they may have been made by a smaller, known, animal, whose tracks were subsequently distorted and enlarged by melting. This is no doubt true of some of the footprints found in the Himalaya, but the details of Shipton's photograph are very sharp, indicating that little melting had in fact occurred. Shipton considered the photographs to be particularly good because the tracks were on a thin layer of crystallised snow lying on firm ice, so there was a minimum of distortion as the creature moved its foot forward; this gives a strong basis for elucidating the movements of the foot. The deepest impressions in human tracks are along the outer side of the back of the heel (where the foot first touches the ground with each step) and on the inner side of the hallux (big toe), which is used to propel the foot forward and is the last part of the foot to be in contact with the ground. These details are well known from criminological studies and are clearly seen in his photograph, strongly suggesting that the yeti tracks were made by a creature using human-like bipedal locomotion. Izzard, Reynolds, Howard-Bury and Hagen, among others, all decided that the yeti was bipedal because only a bipedal animal has the distinctive left-right-left-right stride with no overlapping of the prints, and Izzard pointed out that only a bipedal animal would be able to stand with its feet in the 'ten to two' position seen by the Daily Mail expedition.

Bipedalism is often held to be unique in Homo among primates, but it is by no means rare among apes. Gibbons, for example, are habitually bipedal in walking, and all the other apes are capable of bipedalism at certain times. Adriaan Kortlandt (1962) found that the chimpanzees he was studying walked bipedally for about 10-15 per cent of the distance they covered. Further, this is not a recent adaptation of the apes; according to Pilbeam and Simons (1965), 'the Miocene apes and their Oligocene ancestors probably showed a high degree of trunk erectness and doubtless spent much time walking or running bipedally either in trees or on the ground'. So, given the proper conditions, it is not surprising that there is another primate that is bipedal at least part of the time.*

\section{Eyewitness accounts}

At the present time identification of the yeti must be based on eyewitness accounts. Such accounts have been collected by Stonor (1955), Tchernine (1970), Heuvelmans (1959), and many others. Although a few accounts, including Howard-Bury (1922), Tombazi

* Dr Sydney Britton, University of Virginia, found that the captive chimpanzees he was studying walked bipedally when there was snow, probably to keep their hands from getting cold. 
(1925). and Whillens (1970) are by trained observers, by far the greatest number of reports are from indigenous mountain people, from the Karen of Nothern Thailand and Burma to the Sherpas of the Himalaya, who consider the yeti to be just a part of their local fauna of no special significance. These accounts, although emphasising different aspects of the yeti, are generally consistent and seem to be describing the same animal, and their consistency over a large range, from widely different tribal and linguistic stocks which have had little contact with each other, is strong support for their reliability.

They describe the yeti as a stocky ape-like creature, about 150 to $165 \mathrm{~cm}$ tall, covered with short, coarse hair, reddish-brown or greyish-brown in colour, and longer on the shoulders. The large head has a high pointed crown and a marked sagittal crest. Small ears lie close to the head, and the face is hairless and rather flat. The teeth are quite large, though not fangs, and the mouth is wide. The arms are long, reaching to the knees. The yeti normally walks on two legs, with a shuffling gait; he may drop to all fours when in a hurry or climbing over rocks. The feet are large, with two large prehensile toes and three smaller toes. There is no tail.

The fact remains that yeti are very seldom seen, even by the indigenous people. This seems to be due to three main factors: it is very rare and very elusive, knowing how to hide from man, and well adapted to its environment; and investigators have looked for it in the wrong places. The footprints so frequently reported from the high snowfields seem to be made by an animal which is not a resident of the area, but which is using the high passes to get from one forested valley to another. These passes have few trails which can be followed by man or beast; since yeti are forced to use routes also used by man, their tracks are occasionally observed.

But the preferred yeti habitat, the only habitat where there seems to be sufficient food to support a large primate, where the indigenous people say they live, and where their tracks seem to be heading, is the montane forest zone, between 2800 and 4500 metres. In this zone, visibility is very poor; the vegetation is often so dense as to be described as 'impenetrable'; there are numerous declivities in the rock; stream beds cut deeply into the steep mountainsides; there are no trails other than animal trails; foggy days are common; leeches and other insects are troublesome, and there are very few, if any, people. For these reasons, the montane forest habitat of the yeti has been very incompletely studied, though the few expeditions which have entered the high forests to search for yeti for short periods have returned with reports of yeti tracks, faeces, sleeping sites, and hair (Dyhrenfurth 1959).

\section{Yeti 'scalps'}

Several of the monasteries of the Everest region, including Pangboche, Thyanyboche and Khumjung, keep what are alleged to be yeti scalps. These have long been the centre of controversy, but it now seems fairly certain that at least the scalp at Khumjung was 
made from the shoulder of a serow Capricornis sumatraensis, a goatantelope of the Himalaya. But as Hill (1961) points out, the question may not be so simple. Hairs from the Khumjung scalp had a simian character (the symmetrical arrangement of the granules of pigment) which was not seen in the serow sample with which it was compared. Also, parasitic mites collected both from serow and from the Khumjung scalp, raise queries. Mites are often host specific, being found only on one species or a small groups of species. The mite recovered from the serow was Chorioptes bovis, but the mite recovered from the Khumjung scalp, according to Hill, was unusual in respect of the sculpting of the cuticle, the arrangement and conspicuousness of the hairs, and the size of the limbs, all different from Chorioptes; it has yet to be identified.

Some Sherpas insist that they have always said that the Khumjung scalp is a fake, made in imitation of the real yeti scalp of Thyangboche. But the yeti scalps are at least 300 years old, and none of the Sherpas alive today could possibly give reliable information as to their origin or authenticity. On the other hand, their testimony as to the resemblance of the scalps to the head of a yeti is in many cases based on claimed personal observation of both yeti scalps and real yeti. It is interesting to note that eyewitness accounts of the yeti by Sherpas and other mountain people invariably mention the high, pointed, head; all the 'yeti scalps' are similarly high and pointed.

\section{Fossil ancestor}

Any animal existing today must have ancestors, and it may be that the ancestors of yeti can be found among known fossil forms. There are many possibilities, including such forms as Oreopithecus. Australopithecus robustus, and even Homo erectus, but as Hagen (1961), Reynolds (1967), and others suggest, the most likely candidate seems to be Gigantopithecus, a fossil ape known from four mandibles and over 1000 teeth. The mandibles are about twice the size of gorilla mandibles and the teeth are correspondingly large.

Fossilised remains of Gigantopithecus have been found from Bilaspur in India to Kwangsi in China, dating from the Pliocene to the mid-Pleistocene Epochs, the time when the new genus Homo was evolving. By the mid-Pleistocene, about 500,000 years ago, man had controlled fire and had an extensive range of stone, bone, and wood tools, which gave him a significant selective advantage over other primates and, eventually, over the flora and fauna of the world. Following the 'competitive exclusion principle' (Hardin 1960), which states that ecological differentiation is the necessary condition for coexistence, the primates most closely related to Homo (the apes) were forced to become ecologically differentiated or become extinct.

Increasing domination by man coincided with decreasing population and range in other apes; all present-day apes are relict forms which had a much wider range in the Pleistocene Epoch. For example, orang-utan fossils have been found with Gigantopithecus 
fossils in Kwangsi, China, but orang-utans are now confined to the Indonesian islands of Borneo and Sumatra. Gorillas were once found throughout tropical Africa, but are now broken into two populations, one in the deep jungles of West Africa, the other confined to the montane region of central Africa, where some individuals have been found as high as 4050 metres (Schaller 1963).

The same competitive pressures which drove orang-utans to Borneo and Sumatra and gorillas to the mountains of central Africa were also felt by Gigantopithecus, who, it is hypothesised, sought refuge in the mountains of southern Asia. The Himalaya region has long served as a shelter for relict forms which were not able to compete with more successful lowland forms; they include everything from goat-antelopes and musk deer to ticks (Hoogstraal 1970), and new forms are frequently being discovered, reflecting our lack of knowledge of the region. Of the 21 forms of mammals in the Khumbu region near Mt Everest collected by Biswas (1955) on the Daily Mail expedition, four were new to science.

During the Pleistocene Epoch, when Gigantopithecus was under strong competitive pressure from Homo, the Himalaya were rising as much as 2440 to 3050 metres, thus isolating any animals which may have been there during the upthrust and acting as a sanctuary for their descendants. At this time, the Himalaya were covered with mixed forest, which, according to Simons and Ettel (1970), is the typical Gigantopithecus habitat; the mixed forest still exists today, pine, cedar, bamboo, spruce, rhododendron, and hemlock.

\section{Conclusion}

The giant ape known as Gigantopithecus was found throughout southern Asia during the Pleistocene Epoch; as the tool-using genus Homo increased his effects on closely-related forms, Gigantopithecus (which may have been bipedal) was able to survive only in areas where man was not a threat. Such areas are today generally confined to the high mountain forests of the Himalayan chain; that Gigantopithecus might still survive in such areas is indicated by tracks seen by many reputable westerners and by eyewitness accounts of local people.

Expeditions sent in search of the yeti have returned with tracks, faeces, hairs, and other evidence, but have not been able to confirm the existence of the yeti. This seems to be due to a poor research design. The name 'abominable snowman' suggested to earlier expeditions that the yeti would most likely be found in the snowfields, where the tracks had most often been seen. But such a habitat clearly would not support a large primate, whereas the rich Himalayan forests could. These forests are largely unknown, so a preliminary step in the search for the yeti should include a study of the entire ecosystem of the Himalayan forests, quantifying food chains, conducting species censuses, observing animal movements, and living in the hypothesised yeti habitat for at least a complete yearly cycle. Caves especially should be closely investigated, since large deposits of bones of Asian apes have been found in caves in 
several areas; shallow excavations in caves may reveal sub-fossil remains of Gigantopithecus.

\section{Acknowledgments}

This paper has benefited greatly from discussions with Dr and Mrs John Napier, Dr C. J. Sedgwick, Dr James Sackett, Dr Boonsong Lekagul, and Dr George B. Schaller; the first draft was read by Dr Bobker Ali and Dr Harry Hoogstraal, and many of their valuable suggestions have been incorporated. Mr John Edwards Hill kindly showed us the 'yeti' material at the British Museum (Natural History); Dr D. J. Hooijer gave us valuable comments about Gigantopithecus. Our thanks go to Col. James $\mathrm{R}$. Roberts and $\mathrm{Mr}$ John Blower for their generous assistance in Nepal, and to Nima Chottar, our very able Sherpa Sirdar, for his competence in the field. Finally, we owe special thanks to Miss Mary Lamberts for the labour she put into the paper.

\section{References}

BISWAS, B. 1955. Zoological Results of the 'Daily Mail' Himalayan Expedition. Proceedings of the Zoological Society of London. 8(1).

DYHRENFURTH, N.G. 1959. Slick-John Nepal Snowman Expedition. American Alpine Journal. New York.

HAGEN, TONI, 1961. Nepal. Calcutta.

HARDIN, G. 1960. The Competitive Exclusion Principle. Science, 131. April 29. HEUVELMANS, BERNARD. 1959. On the Track of Unknown Animals. London.

HILL, W.C. OSMAN 1961. The Abominable Snowman. Oryx, 6: 86-98.

HOOGSTRAAL, H. 1970. Human Infestation by Ticks in the Himalaya. H. D. Srivastava Commen. Vol., 75-89.

HOWARD-BURY, C.K. 1922. Mount Everest, the Reconnaissance.

IZZARD, RALPH 1955. The Abominable Snowman Adventure. London.

KORTLANDT, ADRIAAN 1962. Chimpanzees in the Wild. Scientific American. May.

POCOCK, R.I. 1941. Fauna of British India. Mammalia. Vol. II Carnivores.

REYNOLDS, VERNON 1967. The Apes. London.

SANDERSON, IVAN. 1960. Abominable Snowmen: Legend Come to Life. Philadelphia.

SCHALLER, G.B. 1963. The Mountain Gorilla. Chicago.

SHIPTON, ERIC 1952. The Mount Everest Reconnaissance Expedition. London.

SIMONS, E., and J. ETTEL 1970. Gigantopithecus. Scientific American. Jan.

SMYTHE, F.S. 1938. The Valley of Flowers.

STONOR, C. 1955. The Sherpa and the Snowman. London.

TCHERNINE, O. 1970. The Yeti. London.

TOMBAZI, A. 1925. Account of a Photographic Expedition to the Southern Glaciers of Kanchenjunga. Bombay.

TSCHERNESKY, W. 1960. A reconstruction of the foot of the Abominable Snowman. Nature, 186. May 7.

\section{The American Buffalo}

Frank Gilbert Roe's exhaustive critical study of The North American Buffalo, first published in the USA in 1951 and revised in 1971, is now published in England for the first time by David and Charles (£9.50). It is pleasant to know that the author started on the study that eventually produced this 992-page work as a result of studying the evolution of English roads, which led him to think that they were probably not originally wild animal tracks, and neither were the Indian trails in America buffalo tracks. 